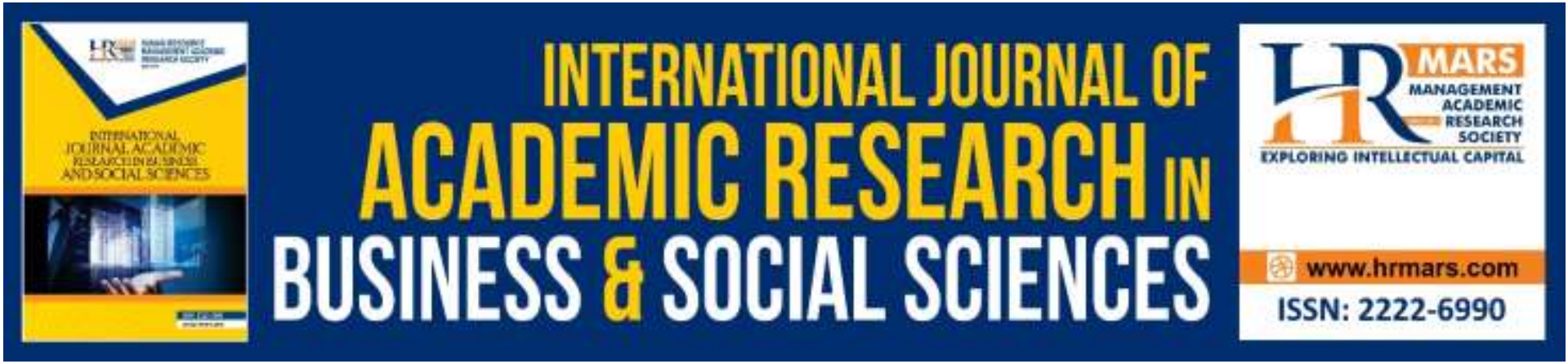

\title{
A Case Study on Outcome Based Education in Comparison with Conventional System
}

Nair Ali Khan, Riaz Muhammad, Shahzad Ali Jamshed, Emadullah

To Link this Article: http://dx.doi.org/10.6007/IJARBSS/v9-i9/6363

DOI: $10.6007 /$ IJARBSS/v9-i9/6363

Received: 19 July 2019, Revised: 22 August 2019, Accepted: 30 September 2019

Published Online: 27 September 2019

In-Text Citation: (Khan, Muhammad, Jamshed, \& Emadullah, 2019)

To Cite this Article: Khan, N. A., Muhammad, R., Jamshed, S. A., \& Emadullah. (2019). A Case Study on Outcome Based Education in Comparison With Conventional System. International Journal of Academic Research in Business and Social Sciences, 9(9), 736-743.

Copyright: (C) 2019 The Author(s)

Published by Human Resource Management Academic Research Society (www.hrmars.com)

This article is published under the Creative Commons Attribution (CC BY 4.0) license. Anyone may reproduce, distribute, translate and create derivative works of this article (for both commercial and non-commercial purposes), subject to full attribution to the original publication and authors. The full terms of this license may be seen

at: http://creativecommons.org/licences/by/4.0/legalcode

Vol. 9, No. 9, 2019, Pg. 736 - 743

http://hrmars.com/index.php/pages/detail/IJARBSS

JOURNAL HOMEPAGE

Full Terms \& Conditions of access and use can be found at

http://hrmars.com/index.php/pages/detail/publication-ethics 


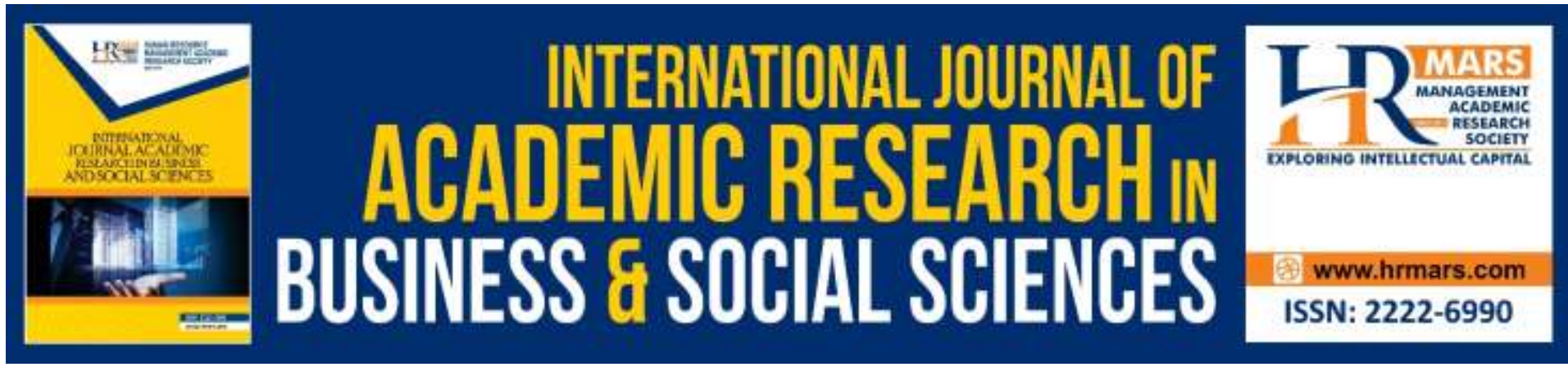

\title{
A Case Study on Outcome Based Education in Comparison With Conventional System
}

\author{
Engr. Nair Ali Khan, Dr. Riaz Muhammad, Engr. Shahzad Ali \\ Jamshed, Engr. Emadullah \\ CECOS University of IT and Emerging Sciences Peshawar KPK Pakistan \\ Emails: engr.nayar@gmail.com, riaz@cecos.edu.pk,shahzadjamshid@gmail.com, \\ emadullah1989@yahoo.com
}

\begin{abstract}
This study is in relation to Washington Accord (WA), Pakistan Engineering Council, aimed for incorporation of Outcome Based Education (OBE) system. Pakistan has signed the accord and has incorporate it in engineering university and is in the process to phase-out the conventional system. For the purpose to know about its implementation status and benefits, this study was conducted in Mechanical department of CECOS University Peshawar. For this purpose one class of forty four students was selected for the analysis of two subjects (Applied Physics and Applied Chemistry) for fall semester 2017. The results revealed that percentage of pass students was in conventional system was $77.27 \%$. in comparison the percentage of pass students was 76.13 in applied physics. In the subject of applied chemistry, percentage of pass students was 68.18 in conventional system and 48.86 in OBE system. In the light of this it was concluded that conventional system is more comfortable for the students. It was also found that all the three domine of Bloom taxonomy were not practices. Due to this, OBE system seems to be a little complicated and difficult for student to follow. The OBE system is still in its preliminary stage and need some improvements in assignments, quizzes and lectures.
\end{abstract}

Keywords: Program Learning Outcomes (PLOs), Washington Accord (WA), Course Learning Outcomes (CLOs). Program Educational Objectives (PEOs).

\section{Introduction}

Several countries reformed their educational system and structure for caliber and competent graduates to achieve the industrial demands (Malan, 2000; Alderson and Martin, 2007). The education intent is to install learning and knowledge, to increase proficiency of all students and lead them with positive posture and values. To contest internationally, quality education shall produce capable pro to erect a potent nation (Biggs \& Tang, 2010). To provide competencies and skills in graduates many models were introduced in institutes. Outcome Based education (OBE) is one of them, which obtain consideration since Washington Accord (1989), Sydney Accord (2001) and Dublin Accord (2002). OBE is a process of assessment and 
evaluation of practices in education to reflect the attainment of expected learning outcomes. OBE is based on bringing out skills of the students. Learning process in conventional system is entirely on lecture based while OBE is student centered based. Standards in the shape of "Graduates Attributes exemplar 2013" has been set by Washington Accord in engineering programs and mandatory to conform by member states. Ghulam Ishaq Khan Institute of Engineering Sciences and Technology (GIKI) and College of Electrical \& Mechanical Engineering (CEME) in 2011 were chosen on exploratory ground. Mechanical department of GIKI and IST have been accredited for four years according to level II. As Pakistan became signatory member of Washington Accord on June 21, 2017, almost all engineering institutes in Pakistan attempting to get accreditation of Washington Accord. OBE structural composition focus on Washington Accord criteria, Bloom Taxonomy and Graduates Attributes. For graduates, Pakistan Engineering Council sets the succeeding twelve attributes. i) Engineering Knowledge ii)Problem Analysis iii) Design/Development of solution iv) Investigation v) Modern Tools Usages vi) The Engineer and Society vii) Environmental and Sustainability viii) Ethics ix) Individual and Team work x) Communication xi) Project Management xii) Life-Long Learning. These attributes are designed in accordance with the guidelines provided in Blooms taxonomy for the successful implementation of OBE. PLOs are the broad outcomes set for a degree program. For example in the current study the program is mechanical engineering, PLOs will be those attributes which are required of set of skills and knowledge as are required in the market. PLOs will define the caliber of the graduate as an engineering graduate. CLOs are course learning outcomes i.e the desired results of the specific subjects; which would inculcate the expected skills in all the students. Bloom's taxonomy provides guidelines for the successful implementation of the set CLOs.

Dr. Benjamin Bloom in 1956 leading the educational psychologists created Bloom's Taxonomy to advance elevated forms of thinking in teaching i-e analyzing and evaluating instead of remembering facts only. Taxonomy refers to classification. The aim was to create a classification system of three domains. i) Cognitive domain refers to mental skills (knowledge) ii) Affective domain refers to development of feelings or emotional areas (Attitude) iii) Psychomotor domain refers to physical skills of the learners.

The aim of this study is to compare conventional and OBE systems on selected attributes. Students will be awarded with grades on Program Learning Outcomes (PLOS) achievements which are directly linked with Course Learning Outcomes (CLOs).

\section{Methodology}

To accomplish the objective of this study, Mechanical department of CECOS University Peshawar was selected in which OBE is carried out parallel to conventional system. Students were assessed via assessment tools against the set curriculum in conventional system while in OBE students were evaluated versus the attributes fixed for program (PLOs) and outcomes for subject (CLOs). A class of Forty four students was chosen from Fall semester 2017 for two subjects (Applied Physics and Applied Chemistry). Different CLOs were defined for each subject which are linked with PLOs defined for Mechanical department. For Applied Physics three CLOs and two PLOs were defined which are :-

CLO1 Comprehend key concepts related to position, velocity, acceleration and vector algebra in Cartesian Coordinate System for particles. 
CLO2 Apply key concepts related to kinetics including work, energy, simple harmonic motion and momentum.

CLO3 Apply key concepts of electrostatic force/field/potential; electric dipole; electric flux and magnetic dipole, magnetic field etc. to real world / engineering.

PLO1 Engineering Knowledge Using mathematical, engineering basics, physical science and knowledge as required and specified here as for grasping engineering problems.

PLO2 Problem Analysis The recognition and formation of research and understanding indicate problems in the field of engineering and solving these problems based upon mathematics, physical science and engineering.

CLO1, CLO2 were linked with PLO1 and CLO3 was linked with PLO2.

For Applied also three CLOs and two PLOs were defined i-e

CL01 Demonstrate working knowledge of applied chemistry and its applications to mechanical engineering field.

CLO2 Identify chemical compounds with harmful effects on environment and propose their control.

CLO3 Apply the acquired knoweldge to identify, formulate and solve engineering problems of chemical nature in field of mechanical engineering.

PLO1 Engineering Knowledge Using mathematical, engineering basics, physical science and knowledge as required and specified here as for grasping engineering problems.

PLO7 Sustainability The awareness and knowledge of effects and durability of solving engineering problems closely related to society and environment and similar issues.

CLO1, CLO3 were linked with PLO1 and CLO2 was linked with PLO7

Results were obtained based upon marks via assessment tools i-e Quizzes, Assignments, Midterm and Final term. In order to achieve final grading for conventional system, the marks obtained by each students in Grade Point Average system a student getting score below $60 \%$ will be considered as fail. So final result is considered as percentage of passed students in the subject. While in OBE system how much PLOs achieved by students to the total PLOs providing the percentage of passing students. Comparing the percentages of both conventional and OBE systems gives a clear picture. Basic formula used for conventional system were $\frac{\text { No.of passed students }}{\text { Total no.of students }} \times 100$

$$
\text { and for OBE system } \frac{\text { No.of achieved PLOs }}{\text { Total no.of PLos }} \times 100
$$

\section{Results and Discussion}

Table1 showing the conventional marks of every student in subject 1 ( Applied Physics) and Subject 2 (Applied Chemistry). In marking criteria $12.5 \%$ is allotted to quizzes, $12.5 \%$ is allotted to assignments, $25 \%$ is allotted to midterm and $50 \%$ is allotted to final term. Thirty 
four students out of forty four students passed the Applied Physics carrying $77.27 \%$ and thirty students passed the Applied Chemistry carrying $68.18 \%$.

Table 1 Conventional results of Applied Physics \& Applied Chemistry

\begin{tabular}{|c|c|c|c|c|}
\hline Subjects & No. of Students & $\begin{array}{c}\text { Passed } \\
\text { Students }\end{array}$ & Failed Students & $\begin{array}{c}\text { \%age of Passed } \\
\text { Students }\end{array}$ \\
\hline Applied Physics & 44 & 34 & 10 & 77.27 \\
\hline $\begin{array}{c}\text { Applied } \\
\text { Chemistry }\end{array}$ & 44 & 30 & 14 & 68.18 \\
\hline
\end{tabular}

Table2 exhibiting academic achievement of OBE system in Applied physics and Applied Chemistry. Key Performance Indicator (KPI) was set to 40\%. It means that a student should get $40 \%$ or above for achievement of PLO. Sixty seven PLOs out of eighty eight PLOs were achieved by the students carrying $\mathbf{7 6 . 1 3} \%$ achievement of total PLOs in Applied Physics and forty three PLOs were achieved carrying $48.86 \%$ achievement of total PLOs in Applied Chemistry.

Table 2 OBE results of Applied Physics \& Applied Chemistry

\begin{tabular}{|c|c|c|c|c|c|}
\hline Subjects & $\begin{array}{c}\text { Number of } \\
\text { Students }\end{array}$ & Total PLOs & $\begin{array}{c}\text { Achieved } \\
\text { PLOs }\end{array}$ & $\begin{array}{c}\text { Not } \\
\text { Achieved } \\
\text { PLOs }\end{array}$ & $\begin{array}{c}\text { \%age of } \\
\text { Passed } \\
\text { Students }\end{array}$ \\
\hline $\begin{array}{c}\text { Applied } \\
\text { Physics }\end{array}$ & 44 & 88 & 67 & 21 & 76.13 \\
\hline $\begin{array}{c}\text { Applied } \\
\text { Chemistry }\end{array}$ & 44 & 88 & 43 & 45 & 48.86 \\
\hline
\end{tabular}

Figure 1 shows Comparison of conventional system and OBE system through chart. Blue bars represents the conventional system result and red bars represents the OBE system results. 


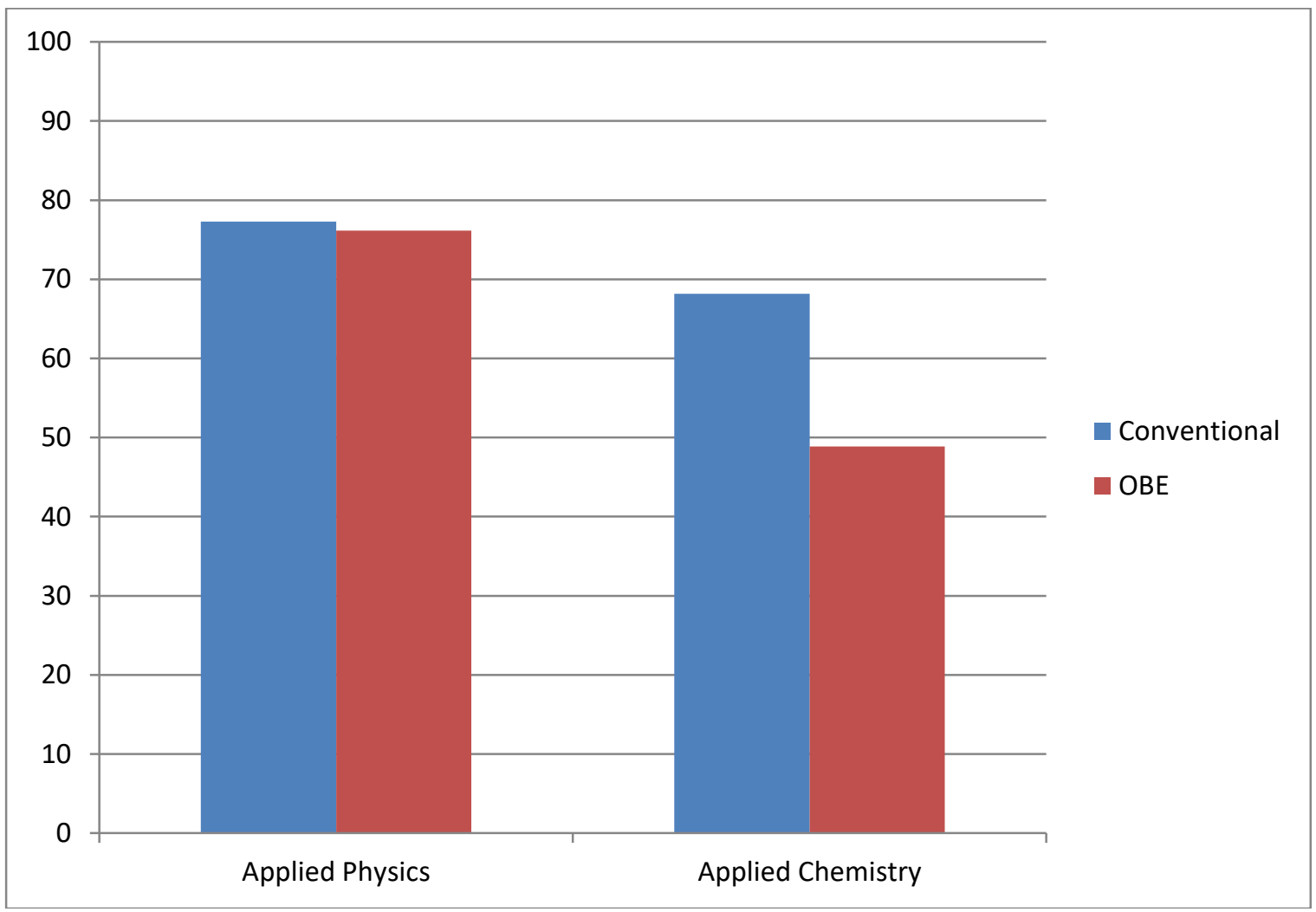

Figure 1 Comparison of Conventional \& OBE system

The above given results of the students are appreciative in because the attainment of the PLOs in both the subjects are above the KPI percentage set for them. PLOs define the different aspects of environment related to applied physics and chemistry. Broadly they require the basic knowledge of the environment related issues. Then the impacts of the applied techniques on the environment. Lastly and most importantly the engineering aspect of these issues and their remedies accordingly.

Similarly the acquired results in the both subjects show promising outcomes in the light of the set CLOs for the subjects. In applied physics the CLOs defined emphasizes on the basic academic knowledge of the concepts of physics such velocity, acceleration etc. Afterwards the application of these concept in the real world, their impacts and issues related with them. Environmental effects of these physical phenomena and how to make effective and productive use of the these physical processes are the main focus of the designed curriculum in the form of CLOs. The other subject i.e applied chemistry has at its core the chemical processes and the principles connected with them. The effects of these chemical processes on environment and the resulting social issues. These concepts, their basic knowledge, application and impacts from engineering point of view are the main focus of the CLOs.

The results a depicted and discussed above in their percentage show promising prospects of the students in the field. The score achieved in applied physics is over $70 \%$ and that of the chemistry is over $40 \%$. Both of them are above the benchmark of KPIs set. These results show that the curriculum as laid out in the form of CLOs are attained to a satisfactory level. Though there are a few lacunas here due to the infancy the educational system being introduced. The assessment tools implemented are mostly borrowed from conventional methodology. The 
proper implementation of the advanced and up to date tools would bring much higher results and hopefully $100 \%$ achievement of the defined CLOs and PLOs in both subjects.

\section{Conclusion}

As a conclusion, students in conventional system shows better achievement than in OBE system. Performance of students evaluated largely in essential facets of OBE through Bloom's Taxonomy is gloomy, because the general course outlay for subjects establish upon on cognitive domain of Bloom Taxonomy. Other two crucial aspects of OBE Psychomotor and Affective domains are completely neglected. The designed curriculum has some deficiencies, i.e they selected few questions rather than selecting the full course. Assessment tools are also the primary causes for discrepancies achieving the coveted results in OBE system.

The study instructed in Mechanical department of CECOS University Peshawar exhibited variances in the conjunction of OBE with conventional system. By additional such studies these imperfections can be addressed. In this research we studied two subjects. Future study may be possibly on whole batch or on all running batches for total subjects. Also Bloom's taxonomy should be totally implanting in courses offered gives improved outcomes. Likewise distinctive techniques besides formal collection of data like questionnaires, faculties and administration possibly employed. A perfect OBE system in engineering disciplines may convey genuine image and potentials of graduates in agonistically progressive engineering domain.

\section{Recommendations}

The study taught here shows some discrepancies between OBE and conventional system. By adding some suggestions this can be addressed. All the aspects of Bloom's Taxonomy that is cognitive, psychomotor and affective domains should be included. Assessment Tools should be altered that is guest lectures, field visits, mini projects etc should be employed. While conducting exam all questions of the final paper should be targeted rather than targeting few questions.

\section{References}

Alderson, A., \& Martin, M. (2007). Outcomes-based education: where has it come from and where it is going? Issues in Education, 17(2), pp. 161-182.

Ahmad, Z., and Mahmood, N. (2010). Effects of Cooperative Learning vs. Traditional Instruction on Prospective Teachers' Learning Experience and Achievement. Ankara University, Journal of Faculty of Educational Sciences, 43(1), pp. 151-164.

Biggs, J., Tang, C., (2010). Teaching for Quality Learning at University. 4th edition. Berkshire, England: McGraw-Hill, Date retrieved: August 5, 2014.

Brindley, G. (2001). Outcomes-based assessment in practice: some examples and emerging insights, Language testing, 18(4), pp. 393- 407.

Deros, M. B., Mohamed, A., Mohamed, N., Ihsan, A. K. A. M. (2012). A Study of Alumni Feedback on Outcome Based Education in the Faculty of Engineering \& Built Environment, University Kebangsaan Malaysia, UKM Teaching and Learning Congress 2011, Procedia - Social and Behavioral Sciences 60, pp. 313 - 317.

Harden, R. M. (2002). Developments in outcome-based education, Medical Teacher. 24(2), pp. 117-120. 
Hashim, H., Mansor, W., Abdullah, S. A. Che., Kamaluddin, M. U., Latip, M. F. Abdul., Yassin, I. M., Rahman, T. K.A., Zakaria, Z., and Kamal, M. M. (2008). Preliminary Results on the Implementation of Outcome-Based Education on The Non-Examinable Computer Engineering Modules, $38^{\text {th }}$ ASEE/IEEE Frontiers in Education Conference, Saratoga Springs, NY.

Heywood, J. (1997). Outcomes Based Engineering Education I: Theory and Practice in the Derivation of "Outcomes" A European Historical Perspective. Frontiers in Education Conference, 0-7803-4086-8 01997 IEEE.

Kember, D. (2005) - Best practice in outcome-based teaching and learning at the Chinese university of Hong Kong.

Mohammad, I. A. A. S. (2009). Implementation of OBE in Engineering Education. Are we there yet? International Conference on Engineering Education (ICEED, 2009), December 7-8, Kuala Lumpur, Malaysia.

Mahmood, K., Khan, K. M., Khan, K. S., and Kian, S. (2015). Implementation of Outcome Based Education in Pakistan: A Step Towards Washington Accord. IEEE 7th International Conference on Engineering Education (ICEED), November 17-18, kanazawa, Japan.

Mousami, V., and Sachin, S. (2015). Assessment of Course Outcomes (COs) in University Affiliated Engineering Programs - Case Study of Course Outcome Attainment. Innovation and Technology in Education (MITE), IEEE International Conference in MOOC, October 1-2, Amritsar, India.

Vijayalakshmi M., Desai, P. D., Joshi, G. H. (2013). Outcome Based Education Performance Evaluation of Capstone Project using Assessment Rubrics and Matrix, IEEE Innovation and Technology in Education (MITE), IEEE International Conference in MOOC, December 20-22, Jaipur, India. 